\title{
Application of Internal Force Analysis of Plastic Deformation in Structural Members to Engineering Design
}

\author{
YIN Jishu ${ }^{1, a}$, WANG Jianbin ${ }^{1}$ \\ ${ }^{1}$ School of Civil Engineering, University of South China, Hengyang, Hunan Province, China \\ ayjs.zc@163.com
}

\begin{abstract}
Keywords: plastic deformation, internal force analysis, design and application
Abstract The internal force analysis for reinforced-concrete structural members is calculated mostly according to the elasticity approach, which increases the amount of reinforcement. The present experiment reveals that if the calculation approach, in which the internal force redistribution after the formation of plastic hinges is taken into consideration and the internal force in a structure is determined through the internal and external equilibrium by the time the structure is about to form a geometric variable system, is applied, members will stay in a balanced-reinforced state to meet the safety requirements. This approach can also help to make full use of the material potential and to obtain better economic benefits during project construction.
\end{abstract}

\section{Introduction}

During construction, the elasticity approach has been commonly used in the calculation of internal forces of reinforced-concrete structures. The internal forces that are calculated by the elasticity approach and considered as the foundation of cross-section reinforcement are definitely able to meet the requirements for structure reliability because it is thought that any cross-section reaches the ultimate bearing capacity will lead to the structural destruction, which is fairly reasonable for statically determinate structures. However, when it comes to hyperstatic reinforced-concrete structures with certain plasticity, the overloaded cross section can load even more without breaking the structure. This indicates that the internal force calculated by the elasticity approach has strength redundancy. To date, in some cases, plastic deformation has been taken into consideration in the internal force calculation. When the structure is about to form a geometrically unstable system, the balance between external and internal forces is applied to analyze the internal force. Many experienced designers often employ the "moment modification method" to calculate the internal force of hyperstatic structures with the purpose of fully taking advantage of the material potential.

\section{Fundamental Principles}

Numerous experiments have demonstrated that on the cross-section of a reinforced-concrete beam in pure bending, the relationship between the bending moment and the curvature is an irregular curve which bends down through the origin. It is shown that the moment-curvature relationship is close to a straight line with a slight slope from the beginning of yield to the final destruction of the cross-section. During this stage, the curvature increases sharply, but the bending moment remains constant and is equal to the ultimate bearing capacity of the cross-section. Therefore, it is thought that this is the stage when the cross sections have yielded. Meanwhile, a large amount of data has also shown that a higher ratio of reinforcement gives rise to a shorter yielding stage and a smaller relative rotation. If there is too much reinforcement, cross sections that lack a yielding stage will display plasticity.

Experiments have indicated that when the internal force of a cross-section of a reinforced-concrete beam reaches its ultimate bearing capacity, the low ratio of reinforcement with no high tensile steels will allow tension steels to first yield, the cross-section to enter the yielding stage, and the beam to move relative to the cross-section as if there is a hinge, which is called a "plastic hinge". 
The difference between the plastic hinge and the ideal hinge is that the ideal hinge permits free rotation but cannot transfer any bending moment, while the plastic hinge is capable of withstanding a bending moment equal to the plastic moment $\mathrm{Mp}$ and allows rotations to occur under the plastic moment Mp only. During the rotation, the plastic hinge can transfer the bending moment Mp but cannot withstand a bending moment larger than the plastic moment $\mathrm{Mp}$. At the same time, the plastic hinge cannot rotate without any limitation and toward the opposite direction. When the compressive concrete of the cross section is crushed, the rotation is up to the ultimate point.

\section{Bending tests of under-reinforced, balanced-reinforced, and over-reinforced concrete members}

Simplified diagram of the test
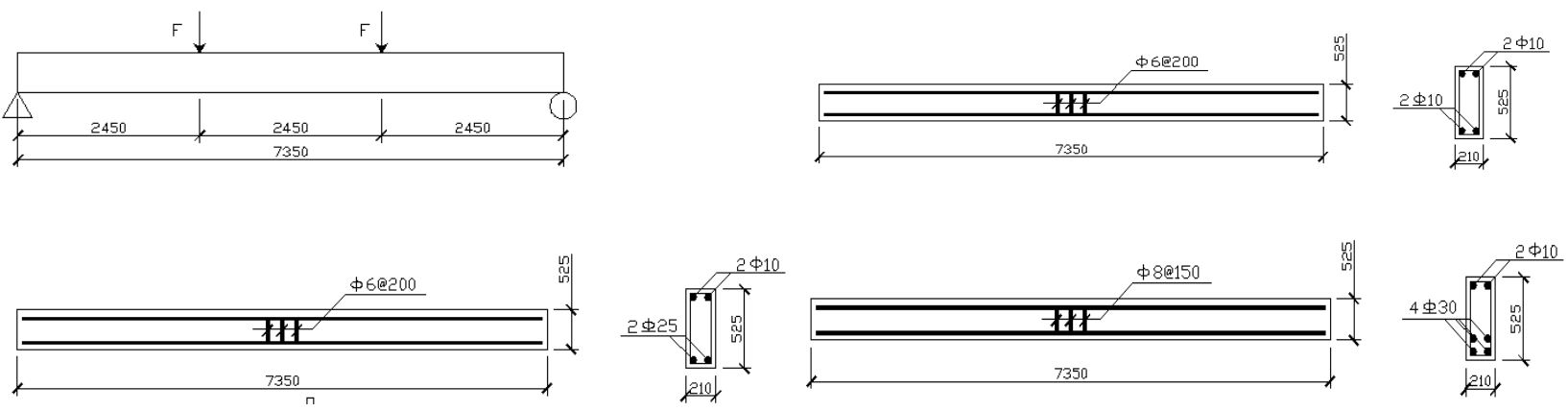

Figure 1

Results of the test

Record of bending tests of reinforced-concrete beam

\begin{tabular}{|c|c|c|c|c|}
\hline Beam type & Concrete grade & $\begin{array}{c}\text { Cracking load } \\
(\mathrm{kN})\end{array}$ & $\begin{array}{c}\text { Failure load } \\
(\mathrm{kN})\end{array}$ & $\begin{array}{c}\text { Crack width } \\
(\mathrm{mm})\end{array}$ \\
\hline Under-reinforced member & $\mathrm{C} 25$ & 6.40 & 9.80 & 0.12 \\
\hline Balanced-reinforced member & $\mathrm{C} 25$ & 8.10 & 58.40 & 0.69 \\
\hline Over-reinforced member & $\mathrm{C} 25$ & 12.50 & 109.50 & 1.12 \\
\hline
\end{tabular}

Analysis of the test

1) The under-reinforced member

It is shown that when the applied load reaches $6.4 \mathrm{KN}$, the member cracks and presents a crushing state within a short time. During the loading process, stress redistribution throughout the member also occurs, but the steel with insufficient strength quickly reaches the yielding state, which makes the member droop prior to failure. Cracks present a small width and a short-time crushing state.

2) The balanced-reinforced member

It is shown that when it gets the $8.1 \mathrm{KN}$ load, cracking in the member occurs and the compression zone of the concrete cross section decreases with redistribution of internal forces. When the stress in the steel increases, the concrete in the compression zone reveals certain plasticity and the stress diagram presents a gentle curve. With the continuously increased load, the stress in the steel goes higher, followed by larger curvature and ending up with the yielding state of the steel. At this point, a plastic hinge, which allows the member to bear more load, is shown in the yielding region of the steel. Cracks keep going up till the stress of the compressive concrete increases sharply to break the member. Cracks present a slow-changing width with load increasing.

3) The over-reinforced member 
It is shown that with $12.5 \mathrm{KN}$ load, cracks appear and soon get to a certain width, leading to a rapid fall of the height of the concrete compression zone. The stress taken by the concrete in the first place is transferred to the steel, which makes the stress in the steel increase rapidly and reach the yielding point. Although there is no failure in the compressive concrete and the member can keep loading, cracks are large enough to cause severe droop of the member.

1. Conclusion of the test:

The balanced-reinforced member exhibits a balanced and slow change in the allowable load, which is highly beneficial for load bearing of the building.

\section{Application}

As shown in Figure 1, a fixed-end beam with a $6 \mathrm{~m}$ span under a uniformly-distributed load is taken as an example for the application of the above analysis.

It is assumed that different cross sections in the beam all share the same size and reinforcement and both the positive and negative plastic moment are $M_{P}=36 \mathrm{KN}$.m. It is also postulated that the uniformly-distributed load is added little by little.

When the uniformly-distributed load $\mathrm{q}_{1}=12 \mathrm{KN} / \mathrm{m}$, according to the elasticity approach,

The bending moment at the fixed end: $M_{A}=M_{B}=\frac{1}{12} q l^{2}=36 K N . m$.

The bending moment at the midspan: $M c=\frac{1}{24} q l^{2}=18 K N . m$.

Where the load of intensity $\mathrm{q}_{1}$ has made the bending moment of the cross-section at the fixed end equal to its ultimate bearing capacity and $\mathrm{q}_{1}=12 \mathrm{KN} / \mathrm{m}$ is the maximum uniformly-distributed load of the beam.

However, as a matter of fact, $\mathrm{q}_{1}$ cannot break the beam due to the control of redundancy, but instead brings the formation of plastic hinges at the cross sections $\mathrm{A}$ and $\mathrm{B}$ of the fixed ends. The crosssection of the midspan has a potential to bear more load of intensity $36-18=18 \mathrm{KN}$, which allows the beam to further load. In the process of further loading, parts of the cross-section at the fixed end are deformed and enlarged after the formation of plastic hinges, while the bending moment remains unchanged as $\mathrm{M}_{\mathrm{P}}=36 \mathrm{KN}$.m. Thus, it has been working as a simply supported beam thereafter as shown in the Figure 2.

When further adding a load $\mathrm{q}_{2}=4 \mathrm{KN} / \mathrm{m}$, calculated as the simply supported beam,

The bending moment at the midspan increases by $\frac{1}{8} q l^{2}=18 K N . m$ :

$M c=\frac{1}{24} q_{1} l^{2}+\frac{1}{8} q_{2} l^{2}=18+18=36 K N . m$.

Where the cross section at the midspan has also become a plastic hinge as reaching the plastic moment.

The whole beam cannot get loaded anymore because of the geometric instability and the ultimate bearing capacity is attained in the structure. Therefore, the ultimate stress in the beam under a uniformly-distributed load is $\mathrm{q}_{1}+\mathrm{q}_{2}=12+4=16 \mathrm{KN} / \mathrm{m}$ instead of $12 \mathrm{KN} / \mathrm{m}$ determined by the elasticity approach. 


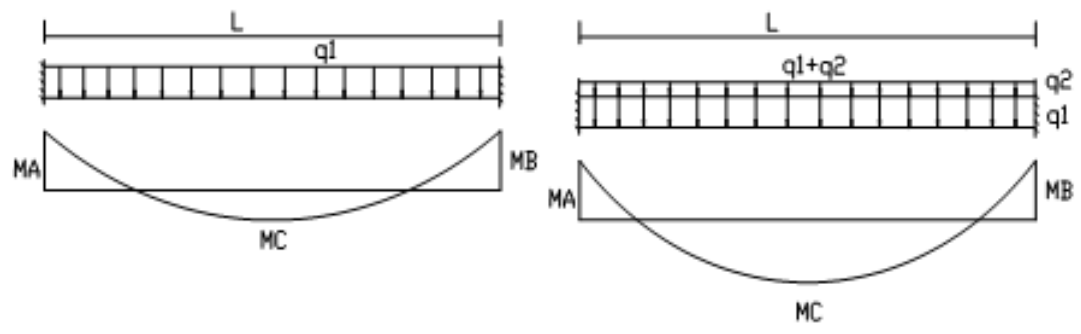

Figure 2

This shows that after the formation of plastic hinges at the fixed end and before the production of the geometrically unstable system, the beam has the potential of further bearing a $4 \mathrm{KN} / \mathrm{m}$ uniformly-distributed load. This potential can be fully utilized in the internal force calculation where plastic deformation is taken into consideration, by which a better economic effect will be obtained.

Prior to the formation of plastic hinges at the cross-sections of the fixed end, the ratio between the bending moment $M_{A}$ and $M_{C}$ is $2: 1$, which is gradually changed thereafter and become 1:1 in the end. This indicates that plastic deformation of material induces a redistribution of internal forces, which is hence called "internal force redistribution analysis with consideration of plastic deformation".

This application tells us three hints:

Hint (1): The destruction of hyperstatic structures with plastic material is a process that plastic hinges are initially formed at one or several cross sections and more plastic hinges appear one after another followed by the increase of load until a geometric variable system is achieved in the structure. The sign of structure failure is the formation of a geometric variable system instead of the yielding in cross-sections.

Hint (2): In the internal force calculation where plastic deformation and internal force redistribution are taken into consideration, the internal force in a structure is determined through the internal and external equilibrium (limit equilibrium) by the time the structure is about to form a geometric variable system.

In this case, the ratio between the fixed-end bending moment and the midspan bending moment changes after the formation of plastic hinges at the cross-sections of the fixed end, but is always sticking to the condition of force balance where the average of the midspan and the two fixed-end bending moments is equal to the midspan bending moment of a simply supported beam.

Hint (3): To a certain extent, the plastic deformation-induced internal force redistribution in hyperstatic structures can be mastered by designers who can control the plastic moment $\mathrm{M}_{\mathrm{P}}$ and the reinforcement of each cross-section.

With a uniformly-distributed load of intensity $16 \mathrm{KN} / \mathrm{m}$, if we assume that the plastic moment of cross sections at the fixed end is $42 \mathrm{KN} . \mathrm{m}$, the beam can be turned into a simply supported beam with $42 \mathrm{KN}$.m bending moment acting on the two fixed ends and a $16 \mathrm{KN} / \mathrm{m}$ uniformly-distributed load acting on the whole beam. The analysis shows that the maximum positive bending moment at the midspan is $30 \mathrm{KN} . \mathrm{m}$ and reveals a corresponding bending moment diagram, by which the reinforcement can be determined to assure the $16 \mathrm{KN} / \mathrm{m}$ uniformly-distributed load. But when $\mathrm{q}_{1}=14$ $\mathrm{KN} / \mathrm{m}$, the plastic hinge will be formed at the fixed end and the stress redistribution will occur on the beam. In the above application with the $36 \mathrm{KN}$.m fixed-end bending moment, the stress redistribution occurs when $\mathrm{q} 1=12 \mathrm{KN} / \mathrm{m}$. If the elasticity approach is used, the calculation will reveal a $48 \mathrm{KN} . \mathrm{m}$ fixed-end bending moment. Therefore, the smaller the value assigned to the fixedend bending moment is than the bending moment calculated by the elasticity approach, the greater degree of internal force redistribution is required. 
The bending moment can be determined by designers to a certain degree, hence providing an easy way for experienced designers to calculate internal forces in reinforced-concrete hyperstatic structures. For continuous beam or fixed-end beam, the plastic moment at cross sections of the fixed end can be designated on our own. If it is a small value, the plastic hinge will arise early at cross sections of the fixed end and the plastic moment at the midspan cross section will have to be increased to meet the condition of force balance. In contrast, the plastic moment at the midspan cross section will be decreased if the designated value is large. This method in which two bending moments can adjust against one another is called the "moment modification method" and is commonly used in engineering design.

However, the moment modification cannot be made without any limitation. If the value assigned to the fixed-end bending moment is much smaller than the bending moment calculated by the elasticity approach, it will be too early for the appearance of the plastic hinge to get a short process of internal force redistribution and excessive rotation of the plastic hinge will cause wider cracks, which cannot meet the application requirements.

\section{Conclusion}

The analysis of the above application reveals that the internal force calculation, in which the internal force redistribution after the formation of plastic hinges is taken into consideration, can reasonably reduce the reinforcement of members and the evenly- and slowly changed stress state in balanced-reinforced members is highly beneficial for load bearing of the building. Additionally, the balanced-reinforced state can reduce the cost of the building, while the structure design has a direct effect on the safety of the building. Therefore, a comprehensive consideration should be taken into the calculation of reinforced-concrete members. The "moment modification method" is often applied to the internal force of hyperstatic structures in order to completely utilize the material potential and achieve better economic benefits. However, the internal force should be calculated following the principles listed below:

(1) To assure the sufficient rotation of plastic hinges at cross sections, the reinforcement has to be restrained to reach the eligible height of the concrete compression zone: $\mathrm{X} \leqslant 0.35 \mathrm{~h}_{0}$, and the steel with better plasticity should be included.

(2) It is not proper that the adjusted cross-section bending moment is less than the $75 \%$ of the bending moment calculated by the elasticity approach.

(3) Within each span, half of the sum of the two adjusted bending moment at the fixed end plus the midspan bending moment should not be less than the maximum midspan bending moment of the simple supported beam.

\section{References}

[1] Technical code for high-rise building concrete structures (JGJ3-2010). China Building Industry Press, 2011. [In Chinese]

[2] Building structure load specification (GB-50009-2012). China Building Industry Press, 2012.

[In Chinese]

[3] Code for Design of Concrete Structures (GB-50010-2010). China Building Industry Press, 2011.

[In Chinese]

[4] Liu Yulin. Computation and comparison of the deflection and deformation mechanics model of concrete slabs in concrete specifications between China and the United States [J]. Highway Engineering, 2016-06. [In Chinese]

[5] Li Guosheng. Disposal and calculation of difficult problems in the design of high-rise reinforced concrete structures [M]. Beijing. China Architecture \& Building Press, 2004. [In Chinese]

[6] Wang Mengfu and Wu Wenqi. Analysis of shear redistribution effect of reinforced concrete frame columns after appearance of plastic hinges[J] Engineering Earthquake Resistant and Retrofitting, 2015-04. [In Chinese] 
[7] Yao Jitao, Song Can and Liu Wei. Reliability analysis of crack control of concrete flexural members [J]. Journal of Civil Engineering 2017, Vol. 50. [In Chinese] 